\title{
DESIGN DRIVEN INOVATION PARA ECONOMIA CRIATIVA: em busca do fomento de inovação de significado para o Portomídia
}

Tarciana Araújo Brito de Andrade

Universidade Federal de Pernambuco andrade.tarci@gmail.com

Leonardo Augusto Gómez Castillo, PhD.

Universidade Federal de Pernambuco leonardo.a.gomez@gmail.com

Aline Cesário Matoso

Universidade Federal de Pernambuco alinecmatoso@gmail.com

André Oliveira Arruda

Universidade Federal de Pernambuco zaca.conteudo@gmail.com

Guilherme Azevedo

Universidade Federal de Pernambuco gui_azevedo@yahoo.com.br

Marcela Araújo de Freitas Brito

Universidade Federal de Pernambuco marcela_fbrito@hotmail.com

Resumo: A nova lógica econômica do mundo pede flexibilidade, se alimenta dos ativos culturais e criativos para gerar valor intangível e competitividade, buscando inclusive legitimar o uso da imaginação nas esferas pública, privada e na sociedade. Qualquer instituição, conglomerado de empresas ou cidade, tem potencial para investir em Economia Criativa. Para tanto, enxerga-se cada vez mais a necessidade de estimular as ideias de Design Driven Innovation (DDI), que primam pelo fomento de redes colaborativas multidisciplinares, no intuito de gerar inovações de significados. Entende-se Inovação de Significado como uma estratégia que se alimenta do capital intelectual e cultural de uma rede de pessoas no intuito de atribuir novos significados ao consumidor final, e prospectar novas atuações de mercado. Tem-se ciência que envolver diferentes stakeholders, dos diversos setores criativos, é uma tarefa árdua, não obstante estratégica para uma economia emergente não estar tão dependente das commodities. Neste sentido, o presente paper apresenta o referencial teórico da pesquisa de mestrado em Design, que visa entender 
o processo de inovação de significado para: o Portomídia. Uma recente iniciativa do Porto Digital, que almeja promover a Economia Criativa no Recife-PE. Para isto, conta com o apoio da Secretaria do Ministério da Cultura do Brasil e do Núcleo de Gestão do Porto Digital - NGPD. Ao final do artigo, apresentam-se considerações preliminares que ensejam uma atenção especial para o fomento de redes colaborativas como meio para criar valor à economia local.

Palavras-chave: Economia Criativa, Design-Driven Innovation, Inovação de Significado, Porto Digital, Portomídia.

\section{INTRODUÇÃO}

O Relatório de Economia Criativa de 2010 evidencia que apesar da economia mundial ter sofrido a mais severa recessão econômica dos últimos 70 anos, entre 2008 e 2009, os "setores criativos - baseados em conhecimento - se mostraram mais resilientes aos choques externos", apresentando maiores taxas de crescimento, que as indústrias tradicionais, segundo UNCTAD (2010). Neste sentido, a Economia Criativa (EC) surge como uma opção de desenvolvimento para as economias emergentes, pois cerca de $59,7 \%$ destas ainda têm nas commodities mais da metade das suas receitas de exportação, Duinsemberg (2008, p.54).

Averígua-se que para as empresas se manterem no mercado, é necessário mais do que o fomento de uma cultura organizacional, que promova o desenvolvimento de produtos/serviços apenas sob o ponto de vista da melhoria incremental, ou seja, reconfiguração do que já existe, segundo Verganti (2009); Norman \& Verganti (2012). Pois, as barreiras produtivas não são mais intransponíveis e percebe-se que está cada vez mais difícil de se conferir características competitivas sob o ponto de vista tecnológico, pois: "as características técnicas são hoje em dia entendidas como indiscutíveis e não são mais suficientes como elementos de diferenciação", (Bürdek, 2006, p. 367).

Na opinião de Barney (1991), um produto para ser competitivo deve ser: raro, valioso, inimitável e insubstituível. Assim, os novos modelos de negócios devem primar por outros caminhos, como o da Economia Criativa e do Design Driven Innovation, promovendo inovações de significado, para se atribuir valor intangível ao consumidor final.

Percebendo o potencial da Economia Criativa para inovação e empreendedorismo, alguns parques tecnológicos brasileiros passam a investir para além de Tecnologia da Informação (TI), no intuito desenvolver empreendimentos no setor criativo, como: Complexos de Santa Catarina (com o Sapiens Parque) e Rio Grade do Sul (por meio do Parque Tecnológico Vale dos Sinos), de acordo com a ANPROTEC (2012); ABDI (2011).

Segundo a ANPROTEC (2013a), o Brasil conta com cerca de 90 iniciativas de parques tecnológicos e 400 incubadoras de empresas, atuando como promotores da competitividade, da capacitação empresarial, da inovação e da cultura, baseando-se na transferência de conhecimento e tecnologia, no intuito de contribuir para elevar a produção de riqueza para uma dada região. 
Conforme o Estudo de Análise Proposições sobre Incubadoras no Brasil, confeccionado pela ANPROTEC (2012a), as incubadoras inicialmente eram focadas em levar ao mercado tendências tecnológicas e novas ideias, estando nos dias atuais, também voltadas para o desenvolvimento local e setorial. Neste contexto, o Recife possui, desde 2000 o Porto Digital, parque tecnológico urbano que se apresenta como um dos principais ambientes de inovação do país, sendo reconhecido internacionalmente como um dos dez parques do mundo onde o futuro está sendo criado, de acordo com a publicação digital da revista Business Week em 2009, Porto Digital (2010). Em 2012, amplia seu escopo de atuação de TI para TI e EC, e inaugura em 2013 a primeira sede de uma das suas mais recentes iniciativas, o Portomídia, no intuito de fomentar a Economia Criativa no Recife, para as áreas: design, jogos digitais, multimídia, cine-vídeo-animação, música e fotografia.

O presente artigo almeja entender os objetivos do Portomídia a fim de entender seus processos e propor um processo de inovação de significado, de acordo com o Design Driven Innovation (DDI), de Roberto Verganti, pois se acredita que valerse dos ativos intangíveis, como cultura, criatividade e conhecimento multidisciplinar, para estimular a criação de significado, podem ser uma saída para tornar-se competitivo no mercado.

No primeiro momento, o artigo apresentará o referencial teórico. Em seguida, será apresentado o caso do Portomídia, e, por conseguinte as considerações preliminares da presente pesquisa, advindas do estado da arte, da pesquisa de documental, e dos estudos exploratórios para a identificação dos sujeitos e da realidade existente, como visitas in loco, acesso a palestras e workshops do Porto Digital, e contato com os atores envolvidos.

\section{DESENVOLVIMENTO}

\subsection{Significado}

O século XX "ficou marcado por uma forte fixação na forma como as obras de arte são executadas e pouco sobre seu valor. A perda de sentido daí advinda se tornou evidente na arquitetura, no design e na arte", (BÜRDEK, 2006, p. 297). Contudo, a estética e a semântica vão gradualmente ganhando importância no produto de design com o passar dos anos, Gotzsch (2000). É possível identificar três fases para o desenvolvimento do design industrial europeu:

Em primeiro lugar, a abordagem Funcionalista: a forma do produto foi dominada pela funcionalidade do produto. Em segundo lugar, a integração da Estética. A fim de tornar o produto mais atraente foi concedido mais atenção para o estilo do produto e os elementos decorativos. Em terceiro lugar, podemos distinguir uma abordagem simbólica ou semântica. Símbolos significativos estão incluídos nos produtos que não só dão prazer estético, mas também agregam valor psicológico ao produto. Estes símbolos podem, por exemplo, criar uma afinidade entre o produto e seu usuário (GOTZSCH, 2000, p.01, grifo do autor, tradução nossa). 
Assim, constata-se na atualidade, o crescimento da relevância, no ambiente acadêmico e de mercado, da abordagem semântica, já que as mesmas subsidiam conhecimento para além de uma visão centrada nas características, funções e desempenho, no intuito de compreender o real significado que as pessoas dão às coisas. Os significados, por sua vez:

[...] refletem as dimensões psicológicas e culturais do ser humano. A maneira que as pessoas dão significados aos produtos depende fortemente dos nossos valores, crenças, normas, e tradições. Em outras palavras, refletem o nosso modelo cultural. E que, por sua vez, reflete o que ocorre em nossas vidas pessoais e na sociedade. (VERGANTI, 2012, p. 52).

Os aspectos culturais podem nortear produções vindouras, fortificando aspectos identitários, que contribuem para a formação do imaginário social, o qual corresponde ao conjunto de relações imagéticas que atuam como memória afetivosocial de uma cultura e um substrato ideológico mantido pela comunidade.

[...] o imaginário corresponde a necessidade do homem de produzir conhecimento pela multiplicação do significado, atribuir significados a significados. (FERRARA, 1997, p. 194)

De acordo com Steffen (n.d.), desde meados da década de 70, Jochen Gros e Richard Fischer, integrantes da Academy of Art and Design Offenbach, na Alemanha, desenvolveram a Teoria da Linguagem do Produto, a qual faz a distinção de funções práticas (características ergonômicas, ecológicas e econômicas, por exemplo) e as funções de linguagem do produto (aspectos formais e comunicativos). Mais tarde, Gros divide essas últimas em funções estéticas (aspectos que podem ser observados, independentemente do significado de seu conteúdo), e semânticas. As Semânticas dividem-se entre funções indicativas (as quais explicam as diversas funções práticas de um produto e como ele deve ser utilizado) e Simbólicas.

A função simbólica, por sua vez, refere-se às concepções e associações que vêm à mente das pessoas, enquanto contempla um objeto (por meio do repertório sóciocultural, histórico, aspectos tecnológicos, econômicos e ecológicos), ainda segundo Steffen. Para tanto, considera-se de relevância conhecer as normas culturais e o contexto para compreender a mensagem e o significado de um produto na forma como foi pretendido. Comungando com a linha de pensamento do Offenbach, Löbach (2001) afirma que a percepção do objeto pode atribuir valor simbólico, para além da forma e função, se conseguirem estimular a espiritualidade do homem, ao estabelecer ligações com suas experiências e sensações anteriores.

Os significados trafegam da produção cultural para o cotidiano e também no sentido inverso de maneira fluída e facilitada. Segundo Ferrara (1986), a geração de significados implica a vivência de uma relação entre interpretantes [rede colaborativa multidisciplinar], uma operação de repertórios que reelabora informações anteriores em confronto com novas experiências, podendo nortear o surgimento de significados inesperados nos: produtos, serviços, modelos de negócio, que repercutam inclusive na imagem institucional. 


\subsection{Design-Driven Innovation}

Neste ponto trataremos do conceito estratégias de inovação; e, por conseguinte, serão explicitados os conceitos de intérpretes e de design discourse (rede colaborativa), os quais fazem parte da estratégia para implementação do DDI.

\subsubsection{Estratégia de Inovação}

Verganti (2012) propõe três possíveis estratégias para o fomento de inovações: (i) a primeira é considerada como o território da inovação radical empurrada pela tecnologia, propondo novas alternativas tecnológicas; a (ii) segunda da inovação incremental puxada pelo mercado, que consiste na reconfiguração do que já existe ("fazer melhor o que já fazemos", normalmente as pesquisas de mercado resultam esse tipo de abordagem estratégica, Norman \& Verganti [2012]).

No entanto, este trabalho irá dar enfoque especial à (iii) terceira estratégia disseminada pelo DDI, onde através de criação de novos significados, novas ou antigas tecnologias podem atingir níveis de inovação radicais de significado que implicam descontinuidade com o passado, Garcia \& Calantone (2002).

Segundo Jegou (2001, p.24), as inovações radicais de significado configuram-se como "o motor da inovação é a capacidade para compreender, antecipar e influenciar a emergência de novos significados de produtos", podendo inclusive prospectar novos mercados. Para Verganti (2012), a criação de novos significados torna-se razão pelo qual esses produtos e serviços são consumidos, e promovem a identificação mais subjetiva para com o consumidor final. O gráfico abaixo ilustra como se dá a relação entre essas três estratégias (Figura1).

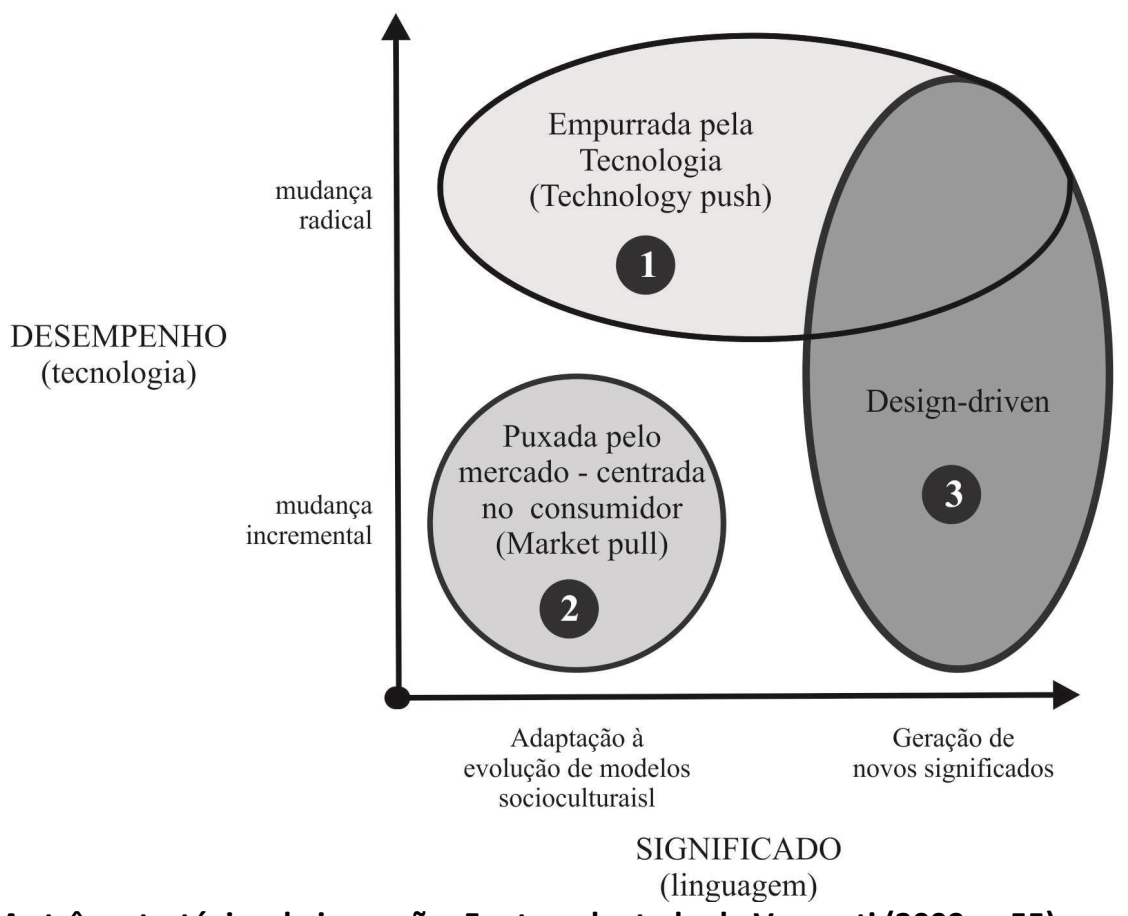

Figura 01 - As três estratégias de inovação. Fonte: adaptado de Verganti (2009. p.55).

Para compreender sobre o que se trata inovações radicais de significado, Verganti (2009) cita o exemplo da empresa Nintendo, que ao criar o console Wii desenvolveu um novo significado para os jogos de vídeo-game. Até então, os jogos eram desenvolvidos tendo em vista melhoria da performance gráfica, ou seja, 
investimento caro em tecnologia, ou seguiam a tendência de um número massivo de jogadores simultâneos por meio da internet, Norman \& Verganti (2012).

O Wii veio para ampliar os horizontes dos games. Rompeu paradigmas e passou a seduzir seus usuários, por meio de um controle simples, com jogos que incentivavam as interações entre os usuários, com movimentação e socialização, prospectando inclusive mercados que não foram pensados, como: utilização do Wii para interação com famílias inteiras e em instituições de longa permanência (LPI).

Apenas com pesquisa de mercado ou pesquisas focadas em usuários a Nitendo não chegaria a este resultado. Os usuários não saberiam responder se fossem perguntadas sobre o que queriam, segundo Norman \& Verganti (2012), já que esta inovação se caracteriza por ser uma inovação radical de significado. Mais tarde, a Microsoft ultrapassa o Wii, com Kinect, uma melhoria incremental do Wii da Nintendo.

Para descrever melhor o processo de inovação incremental e radical, Norman \& Verganti (2012) apresenta the hill-climbing paradigma (Figura 02), evidenciando que um determinado produto " $A$ " pode aprimorar-se através das melhorias incrementais, subsidiadas por design centrados no usuário e pesquisa em design, chegando até " $B$ ". Mas só através das inovações radicais, a mudança: sejam tecnológicas e/ou de significado, poderiam passar para uma coluna diferente, o ponto " $\mathrm{C}$ ", o Wii por exemplo. Só a partir de então poder-se-á iniciar as melhorias incrementais, que almejam prospectar um possível ponto " $D$ ", vide Kinect.

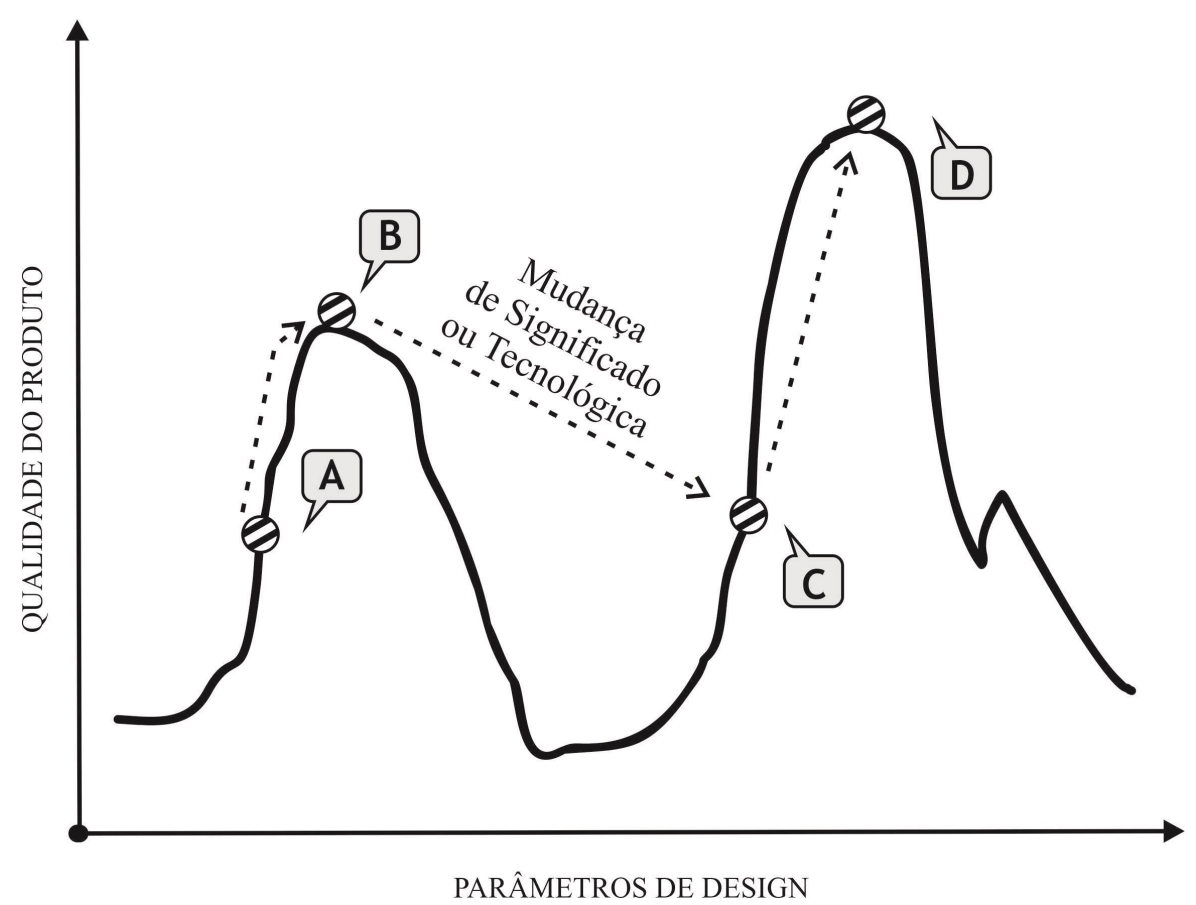

Figura 02 - The hill-climbing paradigm applied to incremental and radical innovation. Fonte: adaptado de Norman \& Verganti (2012).

Assim, vê-se que são necessárias inovações radicais para que seja possível mudar de colina. Estas inovações, por sua vez, apesar de serem difíceis de serem implementados, de acordo com Sandberg (2011), e consideradas de alto risco para o sponsor (patrocinador de recursos), representam uma das maiores fontes de vantagem competitiva no longo prazo, podendo inclusive ampliar o ciclo de vida de um dado produto, Verganti (2012). 
O Wii é apenas um dos muitos exemplos de relevância para o DDI, como: a Alessi (com a Chaleira Kettle 9093 e a linha de produtos para cozinha e Family Follow Fiction, a qual apresentou um crescimento institucional de cerca de 70\%, em apenas 3 anos, segundo Verganti [2012]; Norman \& Verganti [2012]), a Apple (com o iPod ao lado do iTunes que revolucionaram a indústria de música), a Artemide (com a luminária Metamorfosi) e a Swatch (que transformaram o conceito dos relógios no mundo, de joia para adereço de moda).

\subsubsection{Ambiente para emergência de significado}

No mundo, existem diferentes indivíduos e empresas, com expertises de relevância, que analisam um mesmo público-alvo sobre diferentes perspectivas, sem necessariamente serem concorrentes. Dentre estes, pode-se identificar representantes, que podem atuar como ponte para a interpretação de novos significados e linguagens, sendo classificado por Verganti (2012), como intérpretes.

Ainda sob o ponto de vista do autor, entende-se que os intérpretes estão imersos em um laboratório de pesquisa coletivo (Figura 03), que almeja a utilização eficiente das informações que a própria sociedade gera sobre si e sobre o que está pensando e criando, para que possam trabalhar em uma perspectiva multidisciplinar, em prol do pensar sistêmico, caracterizado pela quebra de linearidade e pela valorização da intuição.

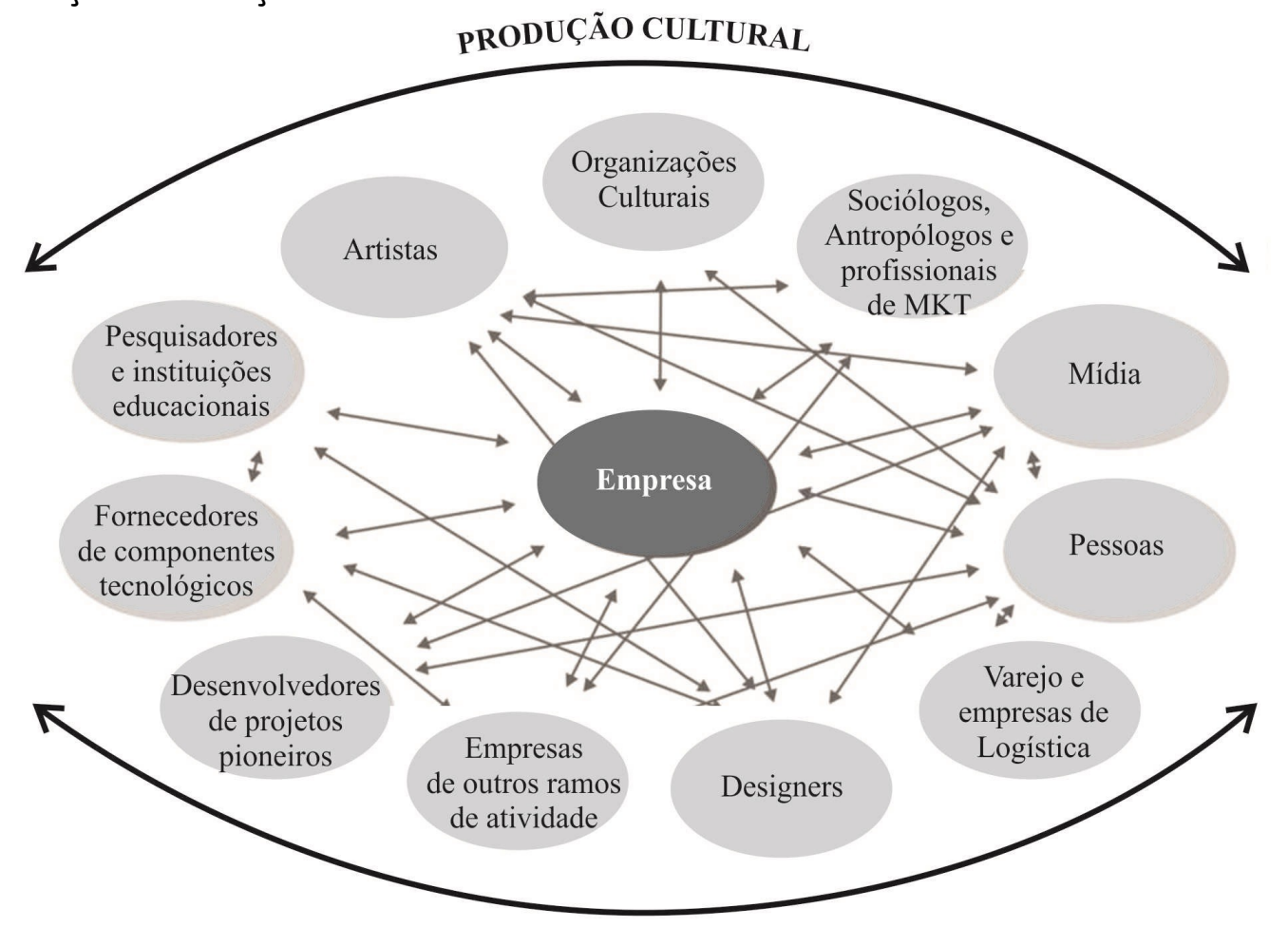

TECNOLOGIAS

Figura 03 - Intérpretes de um laboratório de pesquisa coletivo. Fonte: adaptado Verganti (2009. p.12).

Envolver uma equipe de intérpretes multidisciplinares passa a ser relevante, Verganti (2008). Pois, "as empresas tendem a envolver apenas os intérpretes que já têm uma posição central no segmento em que atuam e essa estratégia pode parecer segura. No entanto, baseia-se mais no passado que no futuro", Verganti (2012, p.154) já que todos olham em uma mesma direção. Portanto, os intérpretes podem estar 
situados nas mais diferentes áreas, podendo ser: artistas, publicitários, designers, músicos, fornecedores de novas tecnologias, pesquisadores, dentre tantos outros que possam agregar, de alguma forma, novos significados a serem desenvolvidos.

Segundo Verganti (2012, p.166) "[...] as inovações radicais podem ser desenvolvidas por círculos colaborativos." A exemplo disto temos o Grupo Memphis que configurou um laboratório de pesquisa de linguagens. Assim como: Wiener Werkstätte, Bauhaus e a escola de Ulm. Tais círculos almejam abstrair da realidade em prol de uma visão mais ampla e profunda acerca da evolução social, cultural e tecnológica, que permita a quebra de paradigmas e criação de novas linguagens e significados, Verganti (2008). O fruto desse processo de pesquisa difuso, Verganti (2012), que integra os intérpretes-chave, é conhecido por design discourse, e baseia a abordagem do DDI.

\subsection{0 caso do Portomídia}

O Portomídia (PM) surge com o intuito de desenvolver estratégias voltadas à promoção da Economia Criativa, no Recife, que possibilitem projetar "a cidade nacional e internacionalmente como um centro de referência neste novo segmento da economia do conhecimento.", conforme o Porto Digital (2012, p.01).

Baseado em quatro pilares, que são: Formação Técnica, Empreendedorismo, Experimentação e Exibição (Figura 03), o Portomídia busca envolver os atores pertencentes ao governo, academia e mercado. Oferece infraestrutura e programas de qualificação com o objetivo de estimular o desenvolvimento de novos modelos de negócios e criar produtos de caráter transmídia, que façam uso intensivo de $\mathrm{TI}$ nas seguintes áreas: design, jogos digitais, multimídia, cine-vídeo-animação, música e fotografia.

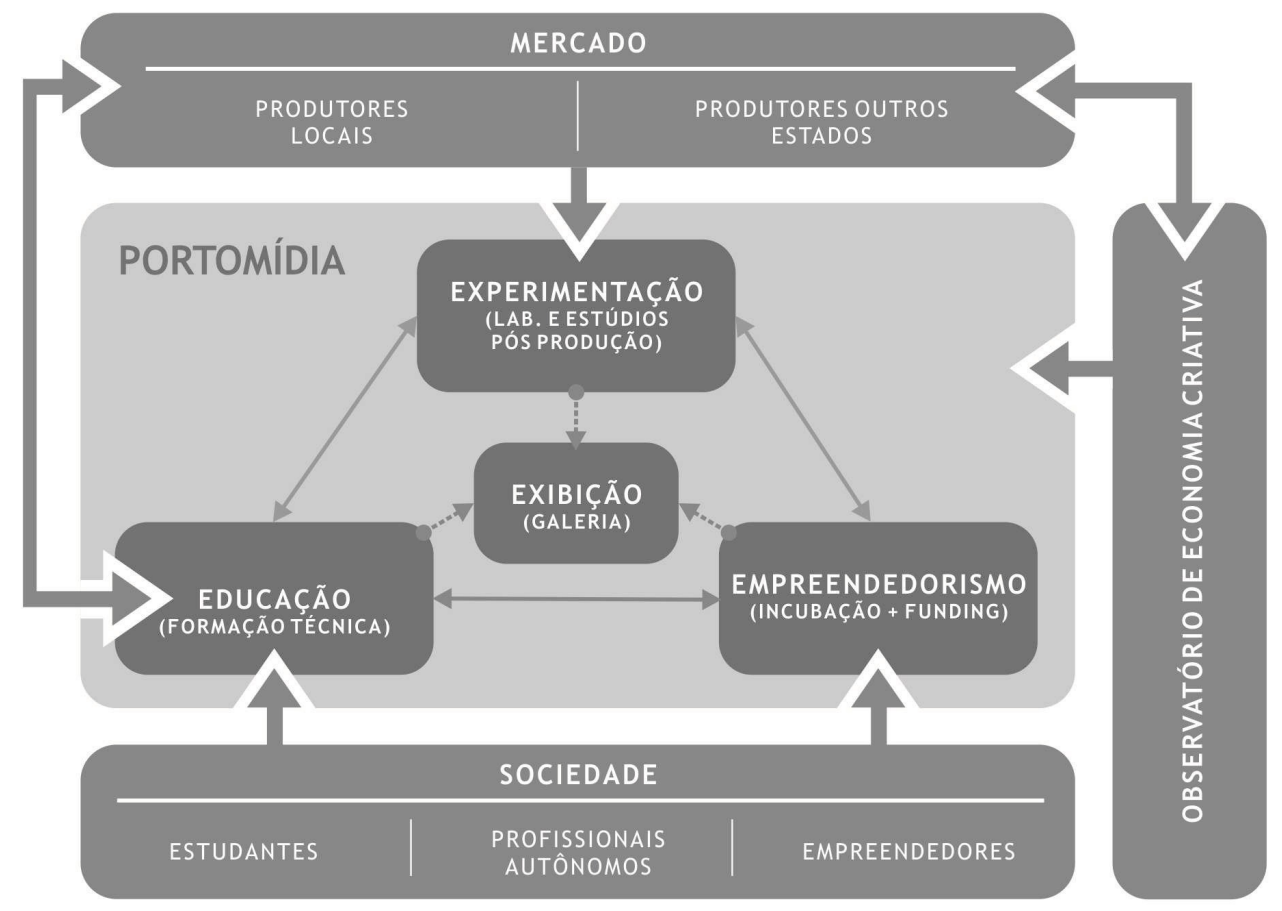

Figura 04 - Pilares do PORTOMÍDIA. Fonte: adaptado de CICTEC (2013, p.22) 
Representantes dessas áreas, de acordo com Porto Digital (2013), sejam estas pessoas físicas ou jurídicas, podem fazer uso dos laboratórios, estúdios, participar dos cursos e eventos de qualificação, além de poder incubar novas ideias na incubadora do Portomídia e utilizar-se da galeria de artes digitais, mediante seleção ou contribuição financeira abaixo do mercado.

Para os projetos incubados, o Portomídia oferece um portfólio de serviços de assessoria e capacitação em gestão empresarial, suporte gerencial e desenvolvimento de produtos, além de completa infraestrutura, com elevado investimento tecnológico, com laboratórios de finalização de cinema, de design (centro de prototipagem) e laboratórios de interatividade e animação. Disponibiliza pontos de trabalho, conexão banda larga e salas de reunião. Iniciou seu processo de seleção para nove projetos incubados em junho de 2012 e vem desde então dando início as suas atividades para, enfim, proporcionar condições favoráveis ao desenvolvimento dos projetos.

Em 2013, inicia o seu processo de seleção para um novo ciclo de incubadas, enquanto que a utilização da infraestrutura advinda pela demanda externa surge por meio dos resultados dos cursos de capacitação, incubadas e demanda espontânea (procura externa pela infraestrutura do PM). O PD também procura analisar o mercado, por meio da realização de pesquisas de mercado, no intuito de oferecer cursos voltados ao interesse do público local, com relação às seis áreas, trazendo inclusive profissionais externos para ministra-los.

\section{CONCLUSÃo}

Assim, percebe-se que o Portomídia vem iniciando o desenvolvimento e formação da rede interpessoal por meio da realização de eventos, mesas redondas e incubadoras por exemplo. $O$ mesmo se mostra bastante receptivo a todos aqueles que queiram corroborar e trocar conhecimento, podendo inclusive firmar acordos que possibilitam a utilização da infraestrutura em troca da oferta cursos, mentorias e/ou mediante o pagamento abaixo do mercado, os ditos programas de residência.

Contudo, sabe-se que a geração de significado para a economia criativa esta diretamente relacionada com a promoção dos bens simbólicos, sendo a cultura considerada como um dos principais insumos para o desenvolvimento das inovações de significado e promoção de diferenciais competitivos. No site institucional do Portomídia, evidencia-se a abordagem cultural como motivo para ampliação do escopo de atuação do PD, de TI para TI e Economia Criativa, ao relatar o potencial da Economia Criativa em Pernambuco, pois tal estado é:

[...] é reconhecidamente um território de emergência cultural. Com fortes influências da cultura popular e o talento natural do pernambucano para a criatividade, a indústria cultural do estado se destaca nas áreas da música - com nomes como Chico Science, Otto e Lenine; do cinema - tendo alguns dos mais famosos cineastas brasileiros da atualidade, Kleber Mendonça Filho e Claudio Assis; e da fotografia. (PORTO DIGITAL, 2013b).

No entanto, não fica clara uma abordagem cultural nos princípios norteadores do PM, que abrange a criatividade, a inovação e o empreendedorismo, mencionados no CICTEC (2013) e por Saboya (2013), o então presidente do Porto Digital desde 2007. 
Estes princípios por sua vez deixam clara a intenção do Portomídia de promover ações que levem ao desenvolvimento de negócios. Tem-se ciência da elevada dependência dos setores culturais brasileiros com relação aos editais de domínio público, faz com que se perca, muitas vezes, a oportunidade de empreender, já que o Brasil não possui uma cultura empreendedora arraigada a sua economia.

As ações do Portomídia podem influir para a configuração de propostas mais independentes dos setores públicos. Fomentar a aproximação dos atores de $\mathrm{TI}$ aos diversos atores criativos, culturais, científicos, tecnológicos e de mercado, pode ser uma fonte para o desenvolvimento de novas propostas, uma fonte para inovação.

Deste modo, poder-se-á dar início ao desenvolvimento de um ambiente propício à emergência de significado, o qual não necessariamente dará resultado no momento em que está sendo estabelecido. Pelo contrario, ele surge como um Metaprojeto, que não pensa apenas em gerar uma solução imediata para um dado projeto, e sim de se libertar dos padrões cognitivos convencionais, do seu entorno e tudo o que esta passível de influenciar direta ou indiretamente esse ambiente de decisão, sem que haja a preocupação de chegar a uma proposta final. O importante é gerar o ambiente.

Portanto, considera-se relevante que o Portomídia fomente relações multidisciplinares entre os diferentes stakeholders do estado. Pois, a mudança de colina não é fácil de ocorrer, não sendo de modo imediatista, sem que haja investimento árduo em trabalho, capital intelectual e abertura dos gestores para uma cultura de mudança. Em vez disso, desafiam se pautam no risco, para possibilitar a geração de ganhos econômicos no longo prazo e potencializar novas oportunidades de mercado.

Deve-se, contudo, levar em consideração que o Portomídia se encontra no processo inicial de estruturação, tanto do ponto de vista de infraestrutura física quanto de configuração de suas próprias atividades. E que tentar configurar novas colinas torna-se, portanto, um desafio para o Portomídia, como meio para que haja a promoção dos significados e a identificação mais subjetiva com o consumidor final.

Neste sentido, percebe-se que o Portomídia possui condições favoráveis a criação de um design discourse essencialmente pernambucano, pois é evidente que Pernambuco dispõe de excelentes pontos fortes e oportunidades para o desenvolvimento desta APL (Arranjo Produtivo Local), como localização estratégica no Recife; experiências em TI bem sucedidas; diversidade cultural do estado; ampliação dos investimentos públicos para a economia criativa e economia da cultura; capital intelectual com acesso a uma formação de qualidade; e incipiente demanda local e regional para a utilização da infraestrutura do Portomídia.

Para tanto, a pesquisa em questão pretende realizar pesquisa qualitativa, por meio de entrevistas semi-estruturadas e workshops, com os stakeholders envolvidos com o Portomídia, a fim de contribuir para que o Porto Digital possa continuar a ser considerado um local onde o futuro está sendo criado. 


\section{REFERÊNCIAS}

ABDI. Parques tecnológicos ampliam atuação. 2011. Disponível em: <http://www.abdi.com.br/Paginas/noticia_detalhe.aspx?i=1811>. Acesso em: 20 jul. 2013.

ANPROTEC. Parques Tecnológicos Investem em Economia Criativa. 2012a. Disponível em: <http://www.anprotec.org.br/publicacao.php?idpublicacao=2352>. Acesso em: 20 jul. 2013.

Estudo, Análise e Proposições sobre as Incubadoras de Empresas no Brasil: Relatório técnico. Convênio de Cooperação Técnica MCTI \& ANPROTEC2012: Brasília. 2012b.

A Anprotec. 2013a. Disponível em: <http://anprotec.org.br/site/pt/aanprotec/>. Acesso em: 20 jul. 2013.

BARNEY, Jay. Firm resources and sustained competitive advantage. Journal of Management. V. 17, n. 1, 1991.

BRASIL. Ministério da Cultura. Plano Nacional da Secretaria da Economia Criativa: política, diretrizes e ações, 2011 - 2014. Brasília: Ministério da cultura, 2011. Disponível em: <www.cultura.gov.br>. Acesso em: 20 jan. 2013.

Portal Brasil. Inovação: Porto Digital.2012. Disponível em: <http://www.brasil.gov.br/sobre/ciencia-e-tecnologia/inovacao/Cases/porto-digital/oporto-da-economia-digital>. Acesso em: 06 ago. 2013.

CICTEC (2013). Porto Digital: Criatividade, Inovação e Empreendedorismo. Pernambuco: Porto digital, 2013. Retrieved from: http://www.slideshare.net/cictec/3seminrio-cictec-porto-mdia-joana-mendona-e-mariana-valena-29-05-2013

DUINSEMBERG, Edna dos Santos. Economia Criativa: Uma opção de desenvolvimento viável?. In: Reis, Ana C. F (org.). Economia Criativa como estratégia de desenvolvimento: uma visão dos países em desenvolvimento. São Paulo, BR: Itaú Cultural \& Garimpo Soluções, 52-73, 2008.

FERRARA, Lucrécia d'Aléssio. A estratégia dos signos: Linguagem, Espaço e Ambiente Urbano. 2. Ed. São Paulo: Ed. Perspectiva, col. Estudos, 1986.

Cidade, imagem e imaginário. In: SOUZA, Célia; PESAVENTO, Sandra (Org). Imagens Urbanas: os diversos olhares na formação do Imaginário Urbano. Porto Alegre: Ed. da UFRGS, 1997. 
GARCIA, Rosanna; CALANTONE, Roger. A critical look at technological innovation typology and innovativeness. The Journal of Product Innovation Management, 19,110-132, 2002.

GOTZSCH, Josiena. Beautiful and Meaningful Products. Symposium on the Dimensions of Industrial Design Research Milan, Milan, 18 mai. 2000. Acesso em: 27 dez 2012.

JEGOU, Francois et. al. Design Driven Toolbox: A Handbook to support companies in Radical Product Innovation. Italia: Evan Consotion, 2001.

LÖBACH, Bernd. Design Industrial: bases para a configuração de produtos industriais, São Paulo: Editora Edgard Blücher Ltda., 2001.

NORMAN, Donald A.; VERGANTI, Roberto. Incremental and radical innovation: design research versus technology and meaning change. Milan, IT: Design Issues. 2011.

PORTO DIGITAL. Porto Digital: 10 years of history and recognition. Pernambuco, BR: PortoDigital, 2010.2 Disponível em: http://www2.portodigital.org/portodigital/ARQUIVOS_ANEXO/Press_Release.PDF. Acesso em: 20 ago. 2013.

- (2012). Chamada pública para incubação de empreendimentos da Economia Criativa no Porto Digital. Pernambuco, BR: Porto Digital. Retrieved from: www2.portodigital.org.

(2013a). Currículo das Incubadoras do Porto Digital. Pernambuco, BR: Porto Digital. Available by Porto Digital.

(2013b). Sobre o Portomídia. Retrieved from: http://www.portomidia.org/\#/portomidia.php

Sandberg, B. (2011). Managing and Marketing Radical Innovations. New York, US: Routledge.

STEFFEN, Dagmar. Design Semantics of Innovation: Product language as a reflection on technical innovation and socio-cultural change. Academy of Finland: Germany. 2007.

UNCTAD. Relatório de Economia Criativa 2010: Economia Criativa: Uma opção de desenvolvimento viável. Nações Unidas, 2010.

VERGANTI, Roberto. Design, Meanings, and Radical Innovation: A Metamodel and a Research Agenda. The Journal Product innovation Managemen, 25, 436-456, 2008.

Design-Driven Innovation. Mudando as regras da competição: a inovação radical de significado de produtos. São Paulo: Canal Certo, 2012. 